\title{
Lower Urinary Tract Functional Assessment of Men Undergoing Radical Prostatectomy: Correlation of Preoperative Clinical and Urodynamic Parameters
}

\author{
Nicholas Faure Walker ${ }^{1}$, Ashan Canagasingham ${ }^{1}$, Danielle Van Diepen ${ }^{1}$, Athina Pirpiris ${ }^{1}$, Vincent Tse ${ }^{1}$, Scott Leslie², \\ Ruban Thanigasalam ${ }^{1}$, Lewis Chan ${ }^{1}$ \\ ${ }^{1}$ Department of Urology and Institute of Academic Surgery, Concord Repatriation General Hospital, University of Sydney, Sydney, NSW, Australia \\ ${ }^{2}$ Department of Urology and Institute of Academic Surgery, Royal Prince Alfred Hospital, University of Sydney, Sydney, NSW, Australia
}

\begin{abstract}
Purpose: To assess baseline clinical and urodynamic profiles of a contemporary cohort of men undergoing radical prostatectomy (RP) as part of the ROSE (Robotic and Open Surgery for Prostate Cancer: A Prospective, Multi-centre, Comparative Study of Functional and Oncological Outcomes) study.

Methods: Men with localized prostate cancer undergoing RP were prospectively recruited to undergo clinical assessment and urodynamic testing prior to surgery as part of a clinical trial. The International Prostate Symptoms Score (IPSS) was used to determine participants' degree of lower urinary tract symptoms (LUTS).

Results: Eighty-five men with a median age of 64.5 years and a median prostate-specific antigen level of $6.3 \mathrm{ng} / \mathrm{mL}$ were prospectively recruited. Of patients with complete baseline data, $36(50.7 \%), 28$ (39.4\%), and 7 (9.9\%) had mild (IPSS $<8)$, moderate (IPSS 8-19), and severe (IPSS > 20) LUTS, respectively. Obstruction was identified in 18 men (29.5\%), and $9(14.8 \%)$ showed detrusor underactivity. Of the 15 patients with detrusor overactivity, $12(80 \%)$ reported overactive bladder (OAB). Of men with urodynamic obstruction, $5(31.3 \%), 10$ (62.5\%), and 1 (6.3\%) reported mild, moderate, and severe LUTS, respectively. Of men without $\mathrm{OAB}, 4(11.8 \%, \mathrm{P}=0.002)$ showed filling phase abnormalities, $13(46.4 \%, \mathrm{P}=0.611)$ had flow rates of $<15 \mathrm{~mL} / \mathrm{sec}$, and $7(30.4 \%, \mathrm{P}=0.767)$ showed obstruction. Of men with mild or no LUTS, $5(20 \%, \mathrm{P}=0.072)$ showed obstruction and $4(16 \%, \mathrm{P}=0.524)$ showed poor contractility.

Conclusion: LUTS and OAB were common in men with localized prostate cancer undergoing RP. Detrusor overactivity and urodynamic filling phase abnormalities were strongly correlated with OAB. IPSS did not show a strong correlation with bladder outflow obstruction or detrusor underactivity. Urodynamic filling abnormalities were found in $11.8 \%$ of men without $\mathrm{OAB}$. Symptomatic and functional assessment may therefore have a role in the preoperative counselling of patients and possibly guide postoperative management of LUTS, especially if OAB is present.
\end{abstract}

Keywords: Urinary bladder, Overactive; Urodynamics; Prostatic neoplasms; Lower urinary tract symptoms

- Research Ethics: This study was approved by the Institutional Review Board of Royal Prince Alfred Hospital Ethics Review Committee (approval number: HREC/16/RPAH/377; Protocol X16-0294; NEAF (AU/1/2717218).

- Conflict of Interest: No potential conflict of interest relevant to this article was reported.

Corresponding author: Nicholas Faure Walker (iD https://orcid.org/0000-0002-7816-9426 Department of Urology and Institute of Academic Surgery, Concord Repatriation General Hospital, University of Sydney, Hospital Road, Concord NSW 2139, Australia

Email: nicholas.faure.walker@gmail.com

Submitted: June 24, 2020 / Accepted after revision: September 18, 2020
This is an Open Access article distributed under the terms of the Cre(cc)
commons.org/licenses/by-nc/4.0/) which permits unrestricted non-commercial use, distribution, and reproduction in any medium, provided the original work is properly cited. 


\section{INTRODUCTION}

Men with prostate cancer are commonly diagnosed after prostate-specific antigen (PSA) testing. The effectiveness of asymptomatic PSA screening has been investigated in several large trials [1-4]. While the benefits of asymptomatic PSA screening at 10 years are unclear, the European Randomized Study of Screening for Prostate Cancer has shown that 570 men need to be screened in order to prevent 1 death at 16 years [3]. Men newly diagnosed with localized prostate cancer, however, are very often at an age when they may have co-existing lower urinary tract symptoms (LUTS). Previous studies have shown that $12.1 \%-56 \%$ of men undergoing radical prostatectomy (RP) have moderate to severe preoperative LUTS $[5,6]$. Their LUTS may be a consequence of bladder dysfunction as well as bladder outflow obstruction from benign or malignant enlargement of the prostate, and the role of PSA screening in this population is not clear.

The Robotic and Open Surgery for Prostate Cancer: A Prospective, Multi-centre, Comparative Study of Functional and Oncological Outcomes (ROSE) study was set up in 2017 to assess oncological and functional outcomes of men undergoing RP (ANZCTR registration number ACTRN12617000296336). The functional outcomes include the identification of urodynamic, dynamic 2-dimensional/3-dimensional (2D/3D) pelvic floor ultrasound (US), and anatomical features, such as prostate volume and urethral length measured using magnetic resonance imaging and pelvic floor US, that may impact urinary function after RP.

Baseline LUTS and their etiology in men newly diagnosed with prostate cancer are not well understood. Previous studies have shown little correlation between the International Prostate Symptom Score (IPSS) and obstruction on urodynamic studies (UDS) for both men and women even when the IPSS is split into voiding and storage symptoms, supporting the adage that "the bladder is an unreliable witness" [7-9]. This study aimed to assess the baseline clinical and urodynamic profiles of LUTS in a contemporary cohort of men undergoing RP and enable a better understanding of the prevalence and etiology of LUTS in men newly diagnosed with localized prostate cancer.

\section{MATERIALS AND METHODS}

Men diagnosed with localized prostate cancer who were undergoing robotic or open RP in the Sydney Local Health District were prospectively recruited for the ROSE study from 2017 to 2020. Baseline questionnaires at the outset of the study collected information on demographic characteristics, clinical parameters, and quality of life.

LUTS were reported using the IPSS and divided into mild ( $0-7$ points), moderate ( $8-19$ points), and severe ( $20-35$ points) cases [10]. Overactive bladder (OAB) was defined as "urinary urgency, usually accompanied by increased daytime frequency and nocturia, with or without urinary incontinence, in the absence of urinary tract infection or other obvious pathology" [11].

All subjects underwent preoperative UDS and functional 2D and 3D pelvic floor US at a single institution (Concord Hospital). Men did not undergo UDS if surgery was planned within 4 weeks from the date of the initial assessment.

Multichannel video-urodynamics using US for imaging were performed, conforming to the standards set by International Continence Society guidelines [12]. The dual catheter technique was employed using a $5 \mathrm{~F}$ vesical pressure line and a $14 \mathrm{~F}$ Nelaton catheter for filling. Suprapubic and transperineal 2D/3D US was performed using a EPIQ-7 US system (Philips, Amsterdam, Netherlands) and C9-2 and X6-1 Matrix transducers (Philips).

Results were collected prospectively using Excel version 10.35 (Microsoft Corp., Redmond, WA, USA) and analysed with SPSS ver. 26.0 (IBM Corp., Armonk, NY, USA) under the guidance of a statistician. Categorical data were compared using the Fisher exact test. Numerical values were shown using the mean when data were normally distributed and the median when data were abnormally distributed. Results were considered to indicate statistical significance if P-values were less than 0.05 .

\section{RESULTS}

In total, 85 men were recruited for the study and had a median age of 64.5 years, with an interquartile range of 59.1 to 69.5 years. The median PSA among the participants was $6.2 \mathrm{ng} / \mathrm{mL}$, with an interquartile range of 5.1 to $9.5 \mathrm{ng} / \mathrm{mL}$. Baseline data are shown in Table 1.

At baseline, 38 men (52.8\%) reported OAB symptoms. Mild, moderate, and severe LUTS were reported by 36 (50.7\%), 28 (39.4\%), and 7 men (9.9\%), respectively.

Baseline clinical data are shown in Table 2. Baseline UDS information is shown in Table 3. The median maximum flow rate was $15 \mathrm{~mL} / \mathrm{sec}$. Approximately one-quarter of men had a maximum urinary flow rate (Qmax) of less than $10 \mathrm{~mL} / \mathrm{sec}$, and half had a Qmax of more than $15 \mathrm{~mL} / \mathrm{sec}$. Detrusor overactivity 
(DO) was observed in 16 men (18.8\%). A loss of compliance (LoC), defined as an increase in detrusor pressure (Pdet) of more than $1 \mathrm{~cm} \mathrm{H} \mathrm{H}_{2} \mathrm{O}$ per $40 \mathrm{~mL}$ of infused volume by the end of filling, was observed in 13 patients (15.3\%), and 24 patients

Table 1. Baseline data $(\mathrm{n}=85)$

\begin{tabular}{lc}
\hline Variable & Value \\
\hline Age $(\mathrm{yr})$ & $64.5(59.1-69.5)$ \\
PSA $(\mathrm{ng} / \mathrm{mL})$ & $6.2(5.1-9.5)$ \\
T stage & \\
T1 & $2(2.4)$ \\
T2 & $54(63.5)$ \\
T3 & $19(22.4)$ \\
T4 & $2(2.4)$ \\
N/A & $8(9.4)$ \\
Gleason score & \\
$3+3$ & $6(7.1)$ \\
$3+4$ & $49(57.6)$ \\
$4+3$ & $8(9.4)$ \\
$4+4$ & $7(8.2)$ \\
$4+5$ & $3(3.5)$ \\
$5+4$ & $2(2.4)$ \\
$5+5$ & $2(2.4)$ \\
N/A & $8(9.4)$ \\
\hline
\end{tabular}

Values are presented as median (interquartile range) or number (\%). PSA, prostate-specific antigen; NA, not available.
Table 3. Baseline urodynamic data $(n=85)$

\begin{tabular}{lc}
\hline Variable & Value \\
\hline Free flow & \\
Voided volume $(\mathrm{mL})(\mathrm{n}=77)$ & $292(20-1,000)$ \\
Qmax $(\mathrm{mL} / \mathrm{sec})(\mathrm{n}=74)$ & $15(2.8-49)$ \\
PVR $(\mathrm{mL})(\mathrm{n}=78)$ & $391(150-860)$ \\
Filling phase - functional capacity $(\mathrm{mL})$ & \\
Qmax $(\mathrm{mL} / \mathrm{sec})$ & $18 / 73(24.7)$ \\
$<10$ & $19 / 73(26.0)$ \\
$10-15$ & $36 / 73(49.3)$ \\
$>15$ & $16(18.8)$ \\
Detrusor overactivity & $13(15.3)$ \\
Loss of compliance & $3(3.5)$ \\
Urge incontinence & $24(28.20)$ \\
Any filling phase abnormality & \\
BOOI & $18 / 61(29.5)$ \\
Obstructed & $16 / 61(26.2)$ \\
Equivocal & $27 / 61(44.3)$ \\
Unobstructed & \\
BCI & $9 / 61(14.8)$ \\
Poor contractility & $38 / 61(62.3)$ \\
Normal contractility & $14 / 61(23.0)$ \\
Strong contractility & \\
\hline
\end{tabular}

Values are presented as median (range) or number (\%).

Qmax, maximum urinary flow rate; PVR, postvoid residual; BOOI, bladder outflow obstruction index; BCI, bladder contractility index.

Table 2. Baseline clinical and CHAMP data $(\mathrm{n}=85)$

\begin{tabular}{|c|c|c|c|c|}
\hline Variable & Complete data & Median (range) & ROSE study, n (\%) & CHAMP data, $\mathrm{n}(\%)$ \\
\hline IPSS - Incomplete emptying & 72 & $1(0-5)$ & & \\
\hline IPSS - Frequency & 72 & $1(0-5)$ & & \\
\hline IPSS - Intermittency & 72 & $1(0-6)$ & & \\
\hline IPSS - Urgency & 72 & $1(0-6)$ & & \\
\hline IPSS - Weak stream & 72 & $1(0-5)$ & & \\
\hline IPSS - Straining & 72 & $0(0-5)$ & & \\
\hline IPSS - Nocturia & 71 & $1(0-5)$ & & \\
\hline IPSS - QoL & 71 & $2(0-6)$ & & \\
\hline IPSS total & 71 & $7(0-35)$ & & \\
\hline Mild LUTS (IPSS 0-7) & & & $36(50.7)$ & $1,008(62.8)$ \\
\hline Moderate LUTS (IPSS 8-20) & & & $28(39.4)$ & $466(29.1)$ \\
\hline Severe LUTS (IPSS 21-35) & & & $7(9.9)$ & $130(8.1)$ \\
\hline OAB reported & & & $38(52.8)$ & $620(37.6)$ \\
\hline
\end{tabular}

CHAMP, Concord Health and Ageing in Men Project ( $\mathrm{n}=1,705$, aged > 70); IPSS, International Prostate Symptoms Score; ROSE, Robotic and Open Surgery for Prostate Cancer: A Prospective, Multi-centre, Comparative Study of Functional and Oncological Outcomes; QoL, quality of life; LUTS, lower urinary tract symptoms; $\mathrm{OAB}$, overactive bladder. 

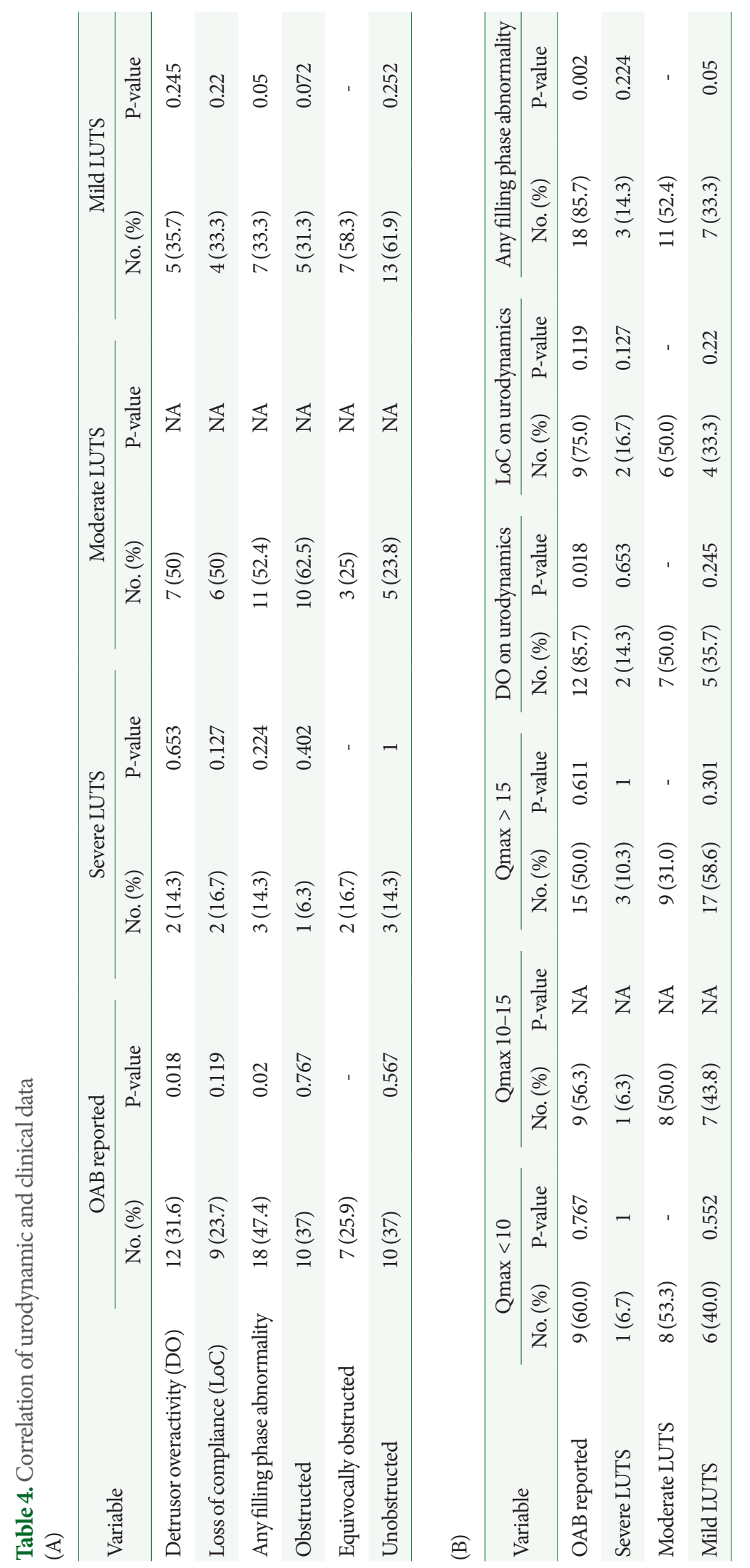

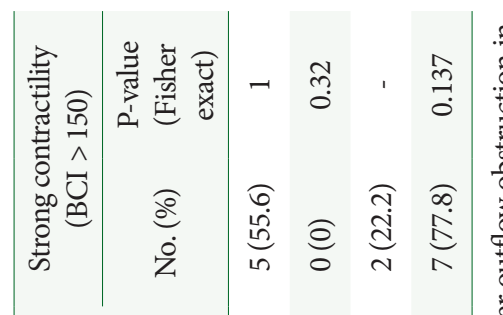

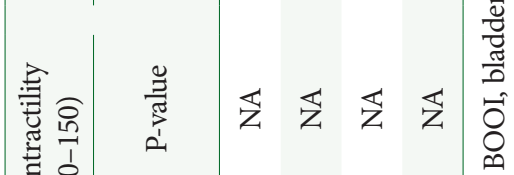

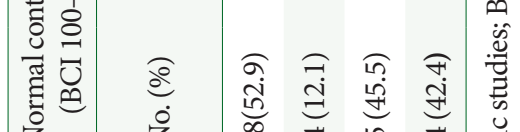

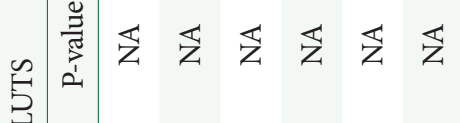

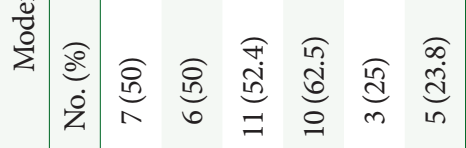

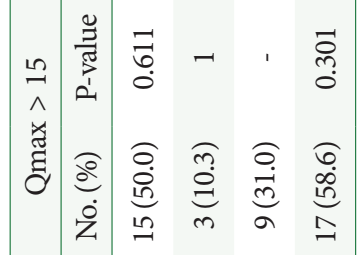

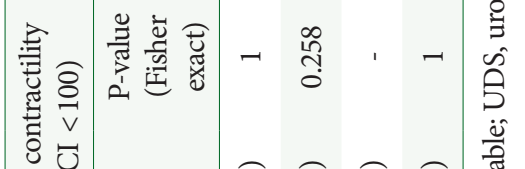



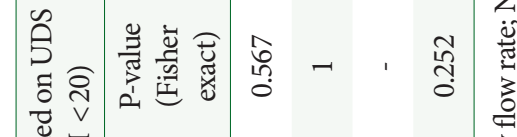

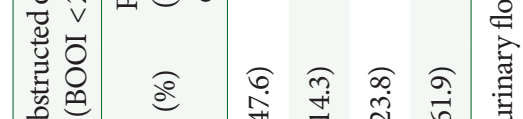

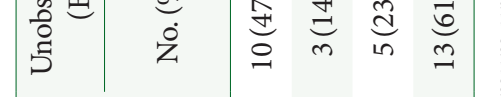

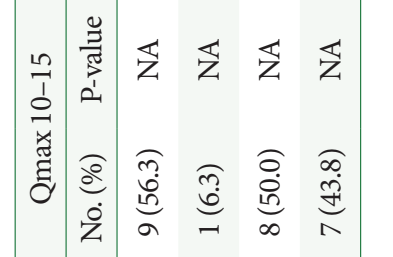

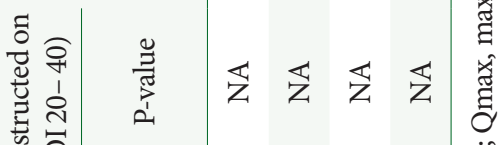

贾

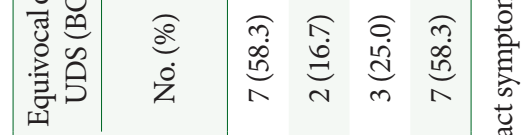

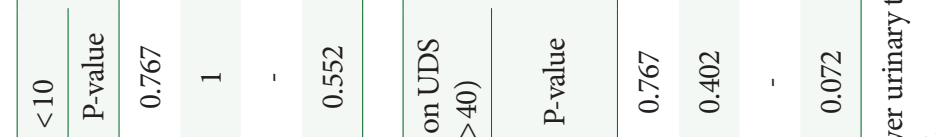

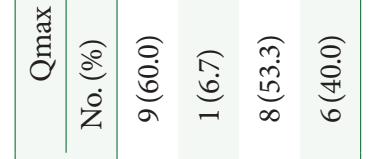

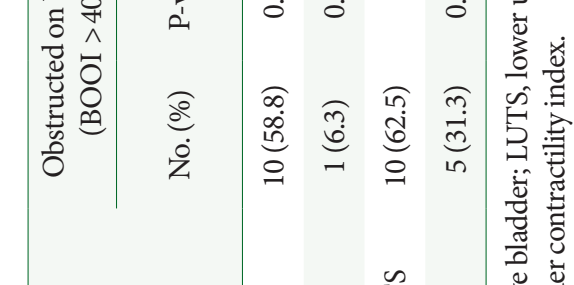

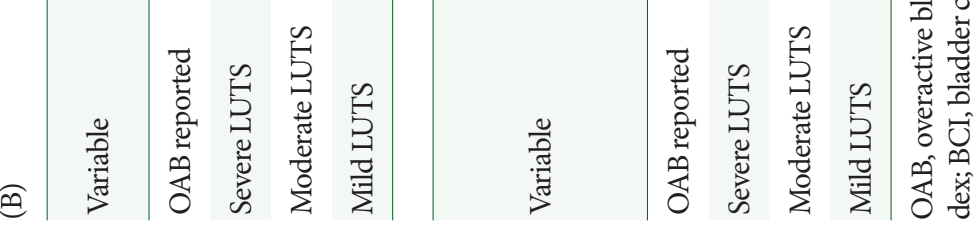


(28.2\%) overall showed at least 1 filling phase abnormality (DO or LoC). Obstruction - defined as a bladder outflow obstruction index $(\mathrm{BOOI}=$ Pdet at $\mathrm{Qmax}-2 \times \mathrm{Qmax})$ of over 40 - was observed in 18 of the men (29.5\%), equivocal obstruction (BOOI 20-40) was observed in 16 of the men $(26.2 \%)$, and no obstruction (BOOI <20) was observed in 27 of the men (44.3\%). A majority of patients (62.3\%) had normal bladder contractility, defined as a bladder contractility index $(\mathrm{BCI}=$ Pdet at Qmax $+5 \times$ Qmax) between 100 and 150. Nine patients $(14.8 \%)$ had detrusor underactivity $(\mathrm{BCI}<100)$ and $14(23 \%)$ had strong contractility (BCI $>150$ ).

The correlations of clinical data with urodynamic findings are shown in Table 4A, B. There was a weak correlation between age and IPSS score $(\mathrm{phi}=0.218, \mathrm{P}=0.067)$ and $\mathrm{OAB}$ ( $\mathrm{phi}=0.230, \mathrm{P}=0.52$ ), but statistical significance was not met. PSA and T stage did not correlate with IPSS or OAB.

Of the 38 men who reported $\mathrm{OAB}$ and had full urodynamic data, $12(31.6 \%, \mathrm{P}=0.018)$ and $18(47.4 \%, \mathrm{P}=0.02)$, respectively, showed DO or a filling phase abnormality on UDS. There was no significant correlation between $\mathrm{OAB}$ and obstruction on UDS. OAB was not correlated with severe LUTS. Of the men with absent or mild LUTS, $7(33.3 \%, \mathrm{P}=0.05)$ had a filling phase abnormality on UDS.

Qmax was not correlated with OAB or IPSS. Of the 15 patients with DO on UDS, $12(80 \%, \mathrm{P}=0.018)$ reported $\mathrm{OAB}$ and $2(14.3 \%, \mathrm{P}=0.653)$ had severe LUTS. A filling phase abnormality was identified in 21 patients, of which $18(85.7 \%, \mathrm{P}=0.002)$ reported $\mathrm{OAB}$ and $3(14.3 \%, \mathrm{P}=0.224)$ had severe LUTS. BOOI and $\mathrm{BCI}$ were not significantly correlated with OAB or IPSS.

Of the men without any $\mathrm{OAB}$ symptoms at baseline, 3 (8.8\%, $\mathrm{P}=0.022)$ had DO, $4(11.8 \%, \mathrm{P}=0.002)$ showed a filling phase abnormality on UDS, $13(46.4 \%, \mathrm{P}=0.611)$ had a flow rate of less than $15 \mathrm{~mL} / \mathrm{sec}, 7(30.4 \%, \mathrm{P}=0.767)$ showed obstruction, and $3(13.0 \%, \mathrm{P}=1.00)$ showed detrusor underactivity. Of the men whose IPSS indicated mild or absent LUTS, 7 (19.4\%, $\mathrm{P}=0.072)$ showed a filling phase abnormality, $13(43.3 \%, \mathrm{P}=$ 0.151) had a Qmax of less than $15 \mathrm{~mL} / \mathrm{sec}, 5(20 \%, \mathrm{P}=0.072)$ showed obstruction, and $4(16 \%, \mathrm{P}=0.524)$ showed detrusor underactivity.

\section{DISCUSSION}

LUTS were common in this cohort of men with a median age of 64.5 years. Nearly half of the men reported moderate or severe LUTS, and 53.8\% reported OAB symptoms prior to sur- gery. The large, population-based European Prospective Investigation into Cancer and Nutrition study found a similar prevalence of storage LUTS in adult men [13]. The Concord Health and Aging in Men Project (CHAMP) study surveyed LUTS among community-dwelling men over 70 years of age (mean age, 77 years) without prostate cancer, and it serves as a source of comparative data to that of the men from the current cohort located in Sydney, since some participants in that study lived within the same geographical vicinity [12]. Despite the older age group in the CHAMP study, $37.2 \%$ of the 1,705 men reported moderate to severe LUTS and $37.6 \%$ reported OAB [14]. The distribution of LUTS in the ROSE study appears to be similar to the cohort of men (median age, 63 years) undergoing RP in the United States examined in the study by Masters and Rice [5], in which 56\% of participants had moderate to severe LUTS. The cohort in the study by Schwartz and Lepor [6] from Switzerland (median age, 61 years) showed a slightly lower proportion of moderate to severe LUTS (43\%). While precise comparisons to the findings of the CHAMP study are not possible, it does appear that the patients diagnosed with localized prostate cancer in the ROSE study had more severe LUTS than the older men in the CHAMP study from a similar region in Australia. This is likely because PSA testing was more likely to have been performed for symptomatic patients than for asymptomatic patients, for whom PSA screening is not routinely performed.

On initial UDS, DO was identified in 16 of the men (18.8\%), and LoC was identified in 3 of the men (15.3\%). Nineteen of the men (29.5\%) showed obstruction, and 9 (14.8\%) showed poor bladder contractility. The prevalence of urodynamic abnormalities in our study appears to be much greater than that found in the prospective study by Majoros et al. [15], in which DO, LoC, obstruction, and poor contractility were shown in $23.8 \%, 1.6 \%, 14 \%$, and $3.2 \%$ of subjects, respectively, across a sample that included 68 men with a mean age of 61.9 years. However, in a prospective study by Giannantoni et al. [16], more baseline UDS abnormalities were identified than in the present study, with DO, LoC, obstruction, and detrusor underactivity being shown in $61.2 \%, 37.1 \%, 59.3 \%$, and $38.8 \%$ of subjects, respectively, across a sample that included 54 men with a mean age of 67 years. Definitions similar to the present study for UDS were used. The differences between these studies and the present study most likely arise from different symptomatology at presentation. It is not clear whether patients in the study by Giannantoni et al. [16] were initially diagnosed via asymptomatic PSA screening or via PSA testing after presenting with 


\section{LUTS.}

The present study is the largest prospective study assessing baseline LUTS and UDS in men undergoing RP for localized prostate cancer to date. Moreover, it is one of the first studies to investigate the correlation between baseline LUTS and UDS findings in a contemporary cohort of men undergoing RP. There was very little correlation between OAB or IPSS and obstruction or bladder contractility. This is consistent with previous studies that have shown poor correlations between IPSS and obstruction on UDS for both men and women, even after the IPSS was split into voiding and storage symptoms, and highlights the difficulty of diagnosing obstruction based purely on presenting symptoms [7-9]. There was, however, a higher correlation between $\mathrm{OAB}$ and filling phase abnormalities in our study. OAB or LoC was found in 18 of the men (47.4\%) who had complete data and reported $\mathrm{OAB}$, and there was a statistically significant correlation between $\mathrm{OAB}$ and LoC. Moreover, of the 15 patients with DO or any filling phase abnormality, $80 \%$ and $85.7 \%$, respectively, reported OAB. Previous studies examining women with $\mathrm{OAB}$ have shown that $26 \%-69.8 \%$ of those with OAB-dry and 35\%-69.8\% of those with OAB-wet showed DO on UDS [17-19]. Fewer studies have examined men. However, the correlation between $\mathrm{OAB}$ and $\mathrm{DO}$ was shown to be stronger for men than for women in studies by both Al-Ghazo et al. [19] and Hashim and Abrams [20], which found that $63 \%$ and $69 \%$ of men with OAB-dry and $93 \%$ and $90 \%$ of men with OAB-wet, respectively, showed DO on UDS. In addition, a study by Al-Zahrani and Gajewski [21] found a weak correlation between $\mathrm{OAB}$ and $\mathrm{DO}$, but a slightly stronger correlation between DO and urgency incontinence in men. These previous studies only analysed UDS data from symptomatic patients.

To our knowledge, this is also the first study of its kind to analyse UDS data and clinical correlations in asymptomatic men as well as in those with LUTS. Of the men who did not report OAB, 4 (11.8\%) showed filling phase abnormalities, approximately half had a Qmax of more than $15 \mathrm{~mL} / \mathrm{sec}, 7$ (30.4\%) showed obstruction, and 3 (13.0\%) showed poor contractility. Of the men whose IPSS indicated mild or no LUTS, 5 (20\%) showed obstruction, and 4 (16\%) showed poor bladder contractility. Clinical assessment including IPSS and (noninvasive) uroflowmetry failed to identify significant bladder pathology in men undergoing RP. The asymptomatic group is of particular concern when being assessed for RP as they would not be routinely identified on a preoperative basis and may be the group most likely to suffer significant functional deterioration following RP.

Following our study, the bladder remains a "unreliable witness" when it comes to bladder outflow obstruction, even though OAB symptoms seem to correlate moderately with underlying bladder pathophysiology. The follow-up stages of the ROSE study will identify whether UDS findings or other clinical parameters can predict functional outcomes following RP.

In conclusion, LUTS and OAB were common in men with localized prostate cancer undergoing RP. DO and UDS filling phase abnormalities were strongly correlated with $\mathrm{OAB}$. The bladder remained an "unreliable witness" for bladder outflow obstruction and bladder contractility in this cohort. Urodynamic filling phase abnormalities were found in $11.8 \%$ of men without OAB, and $20 \%$ of men with no LUTS or with mild LUTS were found to show obstruction on UDS. Symptomatic and functional assessment may therefore have a role in the preoperative counselling of patients and possibly guide postoperative management of LUTS, especially if OAB is present.

\section{ORCID}

Nicholas Faure Walker $\quad$ 0000-0002-7816-9426

Danielle Van Diepen 0000-0003-1692-0832

Athina Pirpiris 0000-0002-4137-6229

Vincent Tse 0000-0002-0993-2176

Scott Leslie 0000-0001-9848-969X

Ruban Thanigasalam 0000-0002-6438-8732

\section{AUTHOR CONTRIBUTION STATEMENT}

- Conceptualization: $V T, S L, R T, L C$

- Data curation: NFW, AC, DVD, AP, VT, SL, RT, LC

- Formal analysis: $N F W, A C, D V D, A P, V T, S L, L C$

- Funding acquisition: $V T, S L, L C$

- Methodology: NFW, DVD, AP, VT, SL, RT, LC

- Project administration: NFW, AP, VT, SL, RT, LC

- Visualization: NFW, VT, SL, RT, LC

-Writing-original draft: $N F W, A C, D V D, A P$

- Writing-review \& editing: $N F W, D V D, A P, V T, S L, R T, L C$

\section{REFERENCES}

1. Andriole GL, Crawford ED, Grubb RL 3rd, Buys SS, Chia D, Church TR, et al. Prostate cancer screening in the randomized Pros- 
tate, Lung, Colorectal, and Ovarian Cancer Screening Trial: mortality results after 13 years of follow-up. J Natl Cancer Inst 2012;104: 125-32.

2. Labrie F, Candas B, Cusan L, Gomez JL, Bélanger A, Brousseau G, et al. Screening decreases prostate cancer mortality: 11-year followup of the 1988 Quebec prospective randomized controlled trial. Prostate 2004;59:311-8.

3. Hugosson J, Roobol MJ, Månsson M, Tammela TLJ, Zappa M, Nelen V, et al. A 16-yr follow-up of the European Randomized study of Screening for Prostate Cancer. Eur Urol 2019;76:43-51.

4. Martin RM, Donovan JL, Turner EL, Metcalfe C, Young GJ, Walsh EI, et al. Effect of a low-intensity PSA-based screening intervention on prostate cancer mortality: the CAP randomized clinical trial. JAMA 2018;319:883-95.

5. Masters JG, Rice ML. Improvement in urinary symptoms after radical prostatectomy: a prospective evaluation of flow rates and symptom scores. BJU Int 2003;91:795-7.

6. Schwartz EJ, Lepor H. Radical retropubic prostatectomy reduces symptom scores and improves quality of life in men with moderate and severe lower urinary tract symptoms. J Urol 1999;161:1185-8.

7. Madersbacher S, Pycha A, Klingler CH, Schatzl G, Marberger M. The International Prostate Symptom score in both sexes: a urodynamics-based comparison. Neurourol Urodyn 1999;18:173-82.

8. Poulsen AL, Schou J, Puggaard L, Torp-Pedersen S, Nordling J. Prostatic enlargement, symptomatology and pressure/flow evaluation: interrelations in patients with symptomatic BPH. Scand J Urol Nephrol Suppl 1994;157:67-73.

9. Blaivas JG. The bladder is an unreliable witness. Neurourol Urodyn 1996;15:443-5.

10. Barry MJ, Fowler FJ Jr, O’Leary MP, Bruskewitz RC, Holtgrewe HL, Mebust WK, et al. The American Urological Association symptom index for benign prostatic hyperplasia. The Measurement Committee of the American Urological Association. J Urol 1992;148: 1549-57; discussion 1564.

11. Abrams P, Andersson KE, Apostolidis A, Birder L, Bliss D, Brubaker $\mathrm{L}$, et al. Recommendations of the International Scientific Committee: evaluation and treatment of urinary incontinence, pelvic organ prolapse and faecal incontinence. Neurourol Urodyn 2018; 37:2271-2.

12. Schäfer W, Abrams P, Liao L, Mattiasson A, Pesce F, Spangberg A, et al. Good urodynamic practices: uroflowmetry, filling cystometry, and pressure-flow studies. Neurourol Urodyn 2002;21:261-74.

13. Irwin DE, Milsom I, Hunskaar S, Reilly K, Kopp Z, Herschorn S, et al. Population-based survey of urinary incontinence, overactive bladder, and other lower urinary tract symptoms in five countries: results of the EPIC study. Eur Urol 2006;50:1306-15.

14. Noguchi N, Chan L, Cumming RG, Blyth FM, Handelsman DJ, Seibel MJ, et al. Lower urinary tract symptoms and incident falls in community dwelling older men: the concord health and ageing in men project. J Urol 2016;196:1694-9.

15. Majoros A, Bach D, Keszthelyi A, Hamvas A, Romics I. Urinary incontinence and voiding dysfunction after radical retropubic prostatectomy (prospective urodynamic study). Neurourol Urodyn 2006;25:2-7.

16. Giannantoni A, Mearini E, Zucchi A, Costantini E, Mearini L, Bini $\mathrm{V}$, et al. Bladder and urethral sphincter function after radical retropubic prostatectomy: a prospective long-term study. Eur Urol 2008; 54:657-64.

17. Hsiao SM, Wu PC, Chang TC, Chen CH, Lin HH. Urodynamic and bladder diary factors predict overactive bladder-wet in women: a comparison with overactive bladder-dry. Int Neurourol J 2019;23: 69-74.

18. Cho KJ, Kim HS, Koh JS, Kim JC. Evaluation of female overactive bladder using urodynamics: relationship with female voiding dysfunction. Int Braz J Urol 2015;41:722-8.

19. Al-Ghazo MA, Ghalayini IF, Al-Azab R, Hani OB, Matani YS, Haddad Y. Urodynamic detrusor overactivity in patients with overactive bladder symptoms. Int Neurourol J 2011;15:48-54.

20. Hashim H, Abrams P. Is the bladder a reliable witness for predicting detrusor overactivity? J Urol 2006;175:191-4; discussion194-5.

21. Al-Zahrani AA, Gajewski JB. Association of symptoms with urodynamic findings in men with overactive bladder syndrome. BJU Int 2012;110(11 Pt C):E891-5. 